\title{
Wisata Super Premium Labuan Bajo: Mengkaji Peran Langsung Dan Tidak Langsung Terhadap Visiting Intention Ditinjau Dari Destination Image Dan Tourist Expectation
}

\author{
Lusy Asa Akhrani', Muhammad Azhar ${ }^{2}$ \\ ${ }^{1}$ Jurusan Psikologi Universitas Brawijaya \\ ${ }^{1}$ Jurusan Psikologi Universitas Brawijaya \\ ${ }^{1}$ lusyasa@ub.ac.id
}

\begin{abstract}
The Indonesian government was planning a super premium tour of Labuan Bajo to be realized in 2020, but the change in this type of tourism resulted in various changes in travel behaviour. This study aims to examine the direct and indirect role of visiting intentions to Labuan Bajo through the destination image and tourist expectation. This research involved 141 tourists who have been and who have a desire to visit Labuan Bajo. Researchers used three scales of analysis, namely the scale of destination image, traveller expectations and visiting intentions. The analysis of this study uses multiple linear regression. The results showed a direct or indirect role of the destination image toward visiting intentions. There are two direct roles obtained, the first direct role from the destination image to the visiting intention and the other direct role from tourist's expectation towards visiting intentions. In contrast, the indirect role of the destination image generated through the expectation of a traveller toward visiting intention. Other results show that there is a simultaneous role between destination image and tourist expectations of the intention to visit Labuan Bajo.
\end{abstract}

Keywords: Destination image, super premium travel, tourist expectation, visiting intention

\begin{abstract}
Abstrak
Pemerintah Indonesia merencanakan wisata super premium Labuan Bajo akan terealisasi tahun 2020, namun perubahan jenis wisata ini menghasilkan berbagai perubahan perilaku berwisata. Penelitian ini bertujuan untuk mengkaji peran langsung maupun tidak langsung terhadap visiting intention ke Labuan Bajo melalui destination image dan tourist expectation. Penelitian ini melibatkan 141 wisatawan yang sudah pernah maupun yang memiliki keinginan untuk berkunjung ke Labuan Bajo. Peneliti menggunakan tiga skala penelitian yaitu skala destination image, tourist expectation dan visit intention. Analisis penelitian ini menggunakan regresi linier berganda. Hasil penelitian menunjukan dari tiga variabel penelitian ini menunjukan terdapat peran langsung maupun tidak langsung citra destinasi terhadap intensi berkunjung. Terdapat dua peran langsung, pertama peran langsung antara destination image terhadap visiting intention dan peran langsung lainnya
\end{abstract}


adalah tourist expectation terhadap intensi berkunjung, sedangkan peran tidak langsung citra destinasi dihasilkan melalui tourist expectation terhadap visiting intention. Hasil penelitian lainnya menunjukan bahwa terdapat peran simultan antara destination image dan tourist expectation terhadap visiting intention ke Labuan Bajo.

Kata Kunci: Destination Image, tourist expectation, visiting intensi, wisata super premium

\section{Pendahuluan}

Labuan Bajo merupakan kota pelabuhan kecil di Pulau Flores, Nusa Tenggara Timur. Labuan Bajo merupakan sebuah pulau yang terletak di Nusa Tenggara Timur dengan beragam wisatanya antara lain seperti pantai Nembrala, danau Kelimutu, pulau Padar, pantai Lasiana, dan lain-lain (Margareth, 2019). Salah satunya Pulau Komodo yang merupakan salah satu new seven wonder of nature oleh new seven wonders foundation (Wahono, 2012). Selain itu Nusa Tenggara Timur juga menempati urutan pertama dalam destinasi dan terjangkau versi Lonely Planet, keindahan alam Nusa Tenggara Timur lebih beragam daripada Bali yang selama ini menjadi tujuan utama turis dari mancanegara (CNN Indonesia, 2019). Sederet keindahan NTT ternyata belum mampu meningkatkan secara signifikan jumlah kunjungan wisatawan ke wilayah ini. Keindahan alam NTT sendiri hanya mampu menarik sejumlah kecil wisatawan. Data jumlah wisatawan yang berkunjung ke NTT hanya sebanyak 1.239.432 pada 2018 (Provinsi Nusa Tenggara Timur dalam Angka, 2019). Data ini berbanding jauh dengan data wisatawan ke Bali yang selama ini menjadi tolok ukur pariwisata Indonesia. Wisatawan Bali pada 2018 terdapat sampai 6.070.473 wisatawan (Badan Pusat Statistik Provinsi Bali, 2020). Hal tersebut menyimpulkan bahwa terdapat perbedaan yang signifikan perihal jumlah wisatawan yang berkunjung ke NTT lebih sedikit daripada Bali. Pemerintah sendiri memiliki rencana besar untuk wisata Labuan Bajo tahun 2020. Labuan Bajo dipersiapkan menjadi destinasi wisata super premium. Perubahan status daerah wisata ini memiliki berbagai dampak perilaku wisatawan, pelaku wisata, warga lokal maupun pemangku kebijakan.

Destinasi wisata super premium Labuan Bajo akan mempersempit segmen pasar wisatawan menjadi kelas menengah ke atas melalui konsekuensi biaya masuk 
kawasan yang direncanakan sebesar 1000 USD atau sekitar 14 juta rupiah. Untuk memenuhi standar sebagai kawasan wisata super premium sendiri pemerintah akan meningkatkan kualitas mulai dari akomodasi, transportasi dan lainnya yang akan menyebabkan pelonjakan harga untuk berkunjung ke destinasi Labuan Bajo (Ramadhan, 2020). Hal tersebut membuat travelling tanpa menggunakan travel agent atau open trip harus direncanakan secara cermat, selain itu kondisi di lokasi wisata harus diperhitungkan dengan cermat untuk meningkatkan visiting intention. Visiting intention merupakan niat seseorang untuk mengunjungi suatu destinasi tertentu dengan jangka waktu tertentu (Whang, Yong, dan Ko, 2015). Sedangkan niat sendiri menurut Ajzen (2005) merupakan sebuah anteseden dari sebuah perilaku yang terlihat. Adapun niat sendiri memiliki fungsi dari tiga penentu utama antaralain adalah sikap, norma subjektif dan kontrol perilaku yang dimiliki individu tersebut (Ajzen, 2005). Sikap yang dimaksud merupakan perasaan individu tentang senang atau tidak senangnya terhadap suatu objek, sedangkan norma subjektif merupakan referensi sosial yang dimiliki individu dalam memilih tindakan tertentu, dan kontrol perilaku merupakan persepsi individu mengenai kemudahan atau kesulitan dalam melakukan perilaku tertentu (Ajzen, 1991). Hal tersebut masing masing dapat menentukan intensi dari seseorang. Kaitan dalam visiting intention adalah adanya kesulitan dalam berwisata ke destinasi Labuan Bajo para wisatawan pada umumnya memiliki kesulitan mulai dari banyak fasilitas umum yang masih tidak terawat, serta masalah mengenai akomodasi mulai dari transportasi darat, udara dan laut (Karunia, 2019).

Penelitian Abubakar \& Ilkan (2016) mengenai visiting intention menunjukan bahwa visiting intention wisatawan sangat berpengaruh pada destination image yaitu dimiliki oleh tempat wisata tertentu di Iran. Selain itu visiting intention secara langsung dipengaruhi oleh Destination Image yang dimiliki oleh turis, berdasarkan penelitian yang dilakukan oleh Whang dkk (2015). Selanjutnya hasil tersebut diperkuat oleh penelitan yang dilakukan oleh Jalilvand (2012) bahwa Destination Image memiliki pengaruh positif serta signifikan terhadap tujuan wisata untuk menentukan visiting intention mereka ke tempat yang indah di Iran. Penelitian yang dilakukan oleh beberapa peneliti sebelumnya 
menunjukan bahwa terdapat hubungan antara visiting intention terhadap Destination Image. Adapun Destination Image merupakan sebuah keyakinan atau pengetahuan mengenai suatu destinasi dan apa yang dirasakan pada saat berwisata (Hanif, Kusumawati \& Mawardi, 2016). Selain itu Hanif dkk (2016) juga mengatakan bahwa setiap destinasi memiliki citra yang berbeda pada setiap destinasinya khusunya destinasi wisata selain itu Destination Image memiliki perbedaan antara satu orang dengan yang lainya hal ini ditentukan berdasarkan penilaian individu tertentu. Sedangkan menurut Coban (2012) dalam penelitiannya menjelaskan Destination Image terdiri dari hasil penilaian rasional atau citra kognitif seseorang dan penilaian yang berasal dari emosional atau citra afektif dari destinasi itu sendiri. Maka dari itu dapat disimpulkan bahwa Destination Image yang unik pada setiap individu dapat menghasilkan perbedaan dalam Destination Image tertentu khususnya Labuan Bajo.

Visiting intention sendiri tidak dapat terlepas dari tourist expectation. Tourist expectation merupakan salah satu faktor penting yang perlu diperhatikan dalam perilaku wisatawan, sehingga pengelola tempat wisata perlu memperhatikan tourist expectation. Menurut Oliver (Verain, 2015) expectation sendiri merupakan keyakinan individu mengenai produk dan akan mempengaruhi perilaku individu selanjutnya. Tourist expectation terbentuk oleh pengalaman pribadi, komunikasi eksternal, WOM, dan image destinasi, dimana image destinasi merupakan sumber terpenting pembentuk tourist expectation (Gnoth, 1997; Bosque, Martin, Collado, dan Salmones, 2009; Bhat dan Qadir, 2013). Tourist expectation merupakan sekumpulan pengetahuan dan keyakinan turis terkait destinasi wisata yang akan membentuk perilaku turis selanjutnya untuk mengambil keputusan akan berkunjung atau tidak ke destinasi wisata tersebut. Tourist expectation merupakan faktor penting bagi destinasi wisata dan kegiatan wisata (Verain, 2015), bila turis turis memili harapan yang rendah pada destinasi wisata makan akan kecil kemungkinan mereka mengunjungi tempat wisata atau berpartisipasi dalam kegiatan wisata. Tourist expectation sendiri terkait erat dengan destination image, menurut Bosque dan Martin (2008) destination image yang baik akan berpengaruh positif terhadap keyakinan turis pada pengalaman yang akan dialami di lokasi 
wisata sehingga akan menghasilkan perilaku berwisata bahkan tidak menutup kemungkinan muncul revisit intention maupun loyalitas wisatawan. Penelitian Valle, Silva, Mendes dan Guerreiro (2006) bertujuan untuk mengkaji tentang faktor-faktor yang mempengaruhi loyalitas wisatawan terhadap sebuah destinasi di Arade, Jerman menjelaskan salah satu faktor yang membentuk perilaku berwisata adalah destination image dan expectation. Hal ini diperkuat oleh hasil penelitian Xia, Jie, Chaolin, dan Feng (2009) meneliti dan menguji turis Guilin, China dengan menggunakan tourist expectations, destination image, perceived quality dan perceived value dan konsekuensi dari tourist complain dan tourist loyalty. Beberapa hasil penelitian menyebutkan bahwa destinasi image dapat mempengaruhi tourist expectation (Xia, dkk, 2009; Myagmarsuren dan Chen, 2011; Gursoy, Chen dan Chi, 2014; Sadeh, Asgari, Mousavi, dan Sadeh, 2012). Destination image dan tourist expectation merupakan dua variabel penting dalam menciptakan intensi berkunjung, mengingat minat berwisata ke Labuan Bajo yang masih belum tinggi meskipun memiliki berbagai potensi dan daya tarik wisata yang tidak kalah menarik dengan destinasi wisata lain di Indonesia, ditambah lagi dengan proyek wisata super premium Labuan Bajo menjadi menarik untuk dijadikan penelitian perilaku wisata.

\section{Metode Penelitian}

Tujuan dari penelitian ini adalah untuk melihat peran dari Destination Image dan tourist expectation terhadap visiting intention ke Labuan Bajo. Penelitian ini menggunakan pendekatan kuantitatif dengan metode analisis Multiple Reggression. Berdasarkan penelitian terdahulu, penelitian ini memiliki hipotesa berupa:

Ha1: Terdapat peran simultan antara Destination Image dan tourist expectation terhadap visiting intention ke Labuan Bajo.

H2: Terdapat peran antara Destination Image Labuan Bajo terhadap tourist expectation

Ha3: Terdapat peran parsial antar tourist expectation terhadap visiting intention ke Labuan Bajo.

Ha4: Terdapat peran parsial antara destination image terhadap visiting intention ke Labuan Bajo. 


\section{Responden Penelitian}

Sample merupakan salah satu bagian dari karakeristik dan jumlah yang dimiliki oleh sebuah populasi (Sugiyono, 2013). Teknik sampling yang digunakan dalam penelitian ini adalah purposive sampling dengan menentukan kriteria responden penelitian terlebih dahulu. Kriteria responden yang ditetapkan peneliti adalah individu yang meluangkan waktu untuk berwisata, ingin berkunjung atau sudah pernah berkunjung ke wisata destinasi Labuan Bajo, dan berusia minimal 17 tahun, karena sudah memiliki kartu tanda pengenal untuk dapat berpergian. Responden penelitian ini merupakan 141 wisatawan yang memiliki intensi untuk berwisata ke Labuan Bajo.

\section{Instrumen Penelitian}

Instrumen yang digunakan pada penelitian ini berupa skala yang mana terdapat dua jenis skala yang berbentuk skala Likert. Skala Likert merupakan skala yang digunakan pada sebuah penelitian untuk mengukur sikap, persepsi maupun pendapat responden mengenai fenomena sosial (Sugiyono, 2013). Pertanyaan yang akan diajukan dalam kuesioner berupa seputar skala theory of planned behavior sesuai dengan indikator menurut (Ajzen dan Fishbein, 1987), skala tourist expectation yang dimodivikasi dari alat ukur milik Jusoh, Masron, Hamid, Shahrin (2013) dan skala citra daestinasi menurut (Coban, 2012).

Peneliti menguji reliabilitas aitem dengan menggunakan item total correlation, yang dimaksudkan untuk dapat mengetahui apakah didalam skala yang disebarkan ada aitem yang gugur ataupun tidak. Kriteria yang ditetapkan peneliti untuk dijadikan batas cut off point adalah $\geq 0.30$, yang artinya jika ada aitem yang sudah mencapai atau bahkan melebihi 0.30 akan dianggap sudah memenuhi batasan. Apabila aitem berada dibawah dari 0.30 akan dianggap memiliki nilai daya beda rendah dan aitem tersebut akan ditetapkan gugur. (Azwar, 2012).

Skala $T P B$ yang digunakan dalam penelitian ini berdasarkan penelitian milik Jehane, Soeprihanto, \& Damanik (2019) dengan total 16 item dengan reliablitas sebesar 0.84. Empat aspek yang dimiliki theory of planned behavior yaitu, sikap, norma subjektif, kontrol perilaku, dan intensi. Skala Destination image yang digunakan dalam penelitian ini berdasarkan penelitian milik Coban (2012) 
dengan total 22 item. Proses uji reliabilitas alat ukur terjadi pengguguran aitem nomor 1 karena tidak memenuhi batas bawah 0.3, dari 22 skala tourist expectation menggunakan milik Jusoh, Masron, Hamid, Shahrin (2013) dengan tiga dimensi dan 26 aitem dan memiliki nilai reliabilitas sebesar 0,94 .

\section{Deskripsi Responden}

Berdasarkan hasil pengambilan data secara daring, jumlah subjek pada penelitian ini sebanyak 141 responden. Responden terbanyak menyatakan tidak pernah ke Labuan Bajo yaitu sebanyak 122 responden dengan persentase sebesar $86,6 \%$. Adapun pada subjek penelitian ini hanya terdapat 1 responden saja yang pernah ke Labuan Bajo lebih dari 2 kali dengan persentase 0,7\%. Hal ini menunjukan meskipun Labuan Bajo memiliki daya tarik pariwisata yang cukup lengkap dan menarik namun masih banyak aitem menjadi 21 aitem dan menghasilkan nilai reliabilitas sebesar 0.89 .

\section{Tabel 1.}

Deskripsi Subjek Berdasarkan Pernah ke Labuan Bajo

\begin{tabular}{cccc}
\hline Data Demografis & Kategori & Jumlah & Persentase \\
\hline \multirow{2}{*}{$\begin{array}{c}\text { Pernah ke Labuan } \\
\text { Bajo }\end{array}$} & 1 Kali & 16 & $11,3 \%$ \\
\cline { 2 - 4 } & 2 Kali & 2 & $1,4 \%$ \\
\cline { 2 - 4 } & > 2 Kali & 1 & $0,7 \%$ \\
\cline { 2 - 4 } & Tidak Pernah & 122 & $86,6 \%$ \\
\cline { 2 - 4 } & & 141 & $100 \%$ \\
\hline
\end{tabular}

Informasi mengenai Labuan Bajo terbanyak didapat responden penelitian melalui media sosial dengan total 89 responden dan memiliki persentase sebesar $63,1 \%$. Adapun informasi yang didapat melalui keluarga pada subjek penelitian ini paling sedikit yaitu sebesar 6 responden dengan persentase 4,3\%. Berdasarkan data demografi yang didapat, rencana perjalanan responden menuju Labuan Bajo dapat dengan beberapa jenis perjalanan, subjek penelitian ini paling banyak ingin atau menggunakan jenis perjalanan open trip sebanyak 53 responden dengan persentase 37,6\%. Sedangkan paling sedikit berjumlah 8 responden dengan jenis perjalanan lain-lain seperti perjalanan dengan alasan pekerjaan atau hanya sekedar jalan jalan dengan persentase sebesar $4,9 \%$. 
Tabel 2.

Deskripsi Subjek Berdasarkan Informasi Mengenai Labuan Bajo dan Pilihan Jenis Perjalanan

\begin{tabular}{|c|c|c|c|}
\hline \multicolumn{4}{|c|}{ Informasi Mengenai Labuan Bajo } \\
\hline Data Demografis & Kategori & Jumlah & Persentase \\
\hline \multirow{5}{*}{$\begin{array}{l}\text { Informasi Mengenai } \\
\text { Labuan Bajo }\end{array}$} & Keluarga & 6 & $4,3 \%$ \\
\hline & Teman & 23 & $16,3 \%$ \\
\hline & Media Sosial & 89 & $63,1 \%$ \\
\hline & $\begin{array}{c}\text { Iklan Jasa } \\
\text { Tour/Open Trip }\end{array}$ & 15 & $10,6 \%$ \\
\hline & Lain-lain & 8 & $5,7 \%$ \\
\hline \multicolumn{2}{|c|}{ Total } & 141 & $100 \%$ \\
\hline \multicolumn{4}{|c|}{ Pilihan Jenis Perjalanan } \\
\hline Data Demografis & Kategori & Jumlah & Persentase \\
\hline \multirow[t]{4}{*}{ Jenis Perjalanan } & Open Trip & 53 & $37,6 \%$ \\
\hline & Solo Traveling & 30 & $21,3 \%$ \\
\hline & Private Tour & 51 & $36,2 \%$ \\
\hline & Lain-lain & 7 & $4,9 \%$ \\
\hline \multicolumn{2}{|c|}{ Total } & 141 & $100 \%$ \\
\hline
\end{tabular}

Tabel 3.

Data Demografi Responden

\begin{tabular}{llcc}
\hline Data Demografis & \multicolumn{1}{c}{ Kategori } & Jumlah & Persentase \\
\hline Jenis Kelamin & Laki-laki & 66 & $46,8 \%$ \\
& Perempuan & 75 & $53,2 \%$ \\
\hline Usia & $17-24$ & 89 & $63,1 \%$ \\
& $25-34$ & 34 & $24,1 \%$ \\
& $35-44$ & 11 & $7,8 \%$ \\
& $45-54$ & 6 & $4,3 \%$ \\
& $55-64$ & 1 & $0,7 \%$ \\
\hline Asal & Jakarta & 0 & $0 \%$ \\
& Jawa Timur & 61 & $43,4 \%$ \\
& Jawa Barat & 32 & $22,6 \%$ \\
& Jawa Tengah & 30 & $21,4 \%$ \\
& Kalimantan & 6 & $4,2 \%$ \\
& Sumatra & 4 & $2,8 \%$ \\
& Sulawesi, Bali & 4 & $2,8 \%$ \\
& Nusa Tenggara Barat & 1 & $1,4 \%$ \\
& Pelajar & 2 & $1,4 \%$ \\
\hline Pekerjaan & Mahasiswa & 1 & $0,7 \%$ \\
& Pekerja & 80 & $56,7 \%$ \\
& PNS & 43 & $30,5 \%$ \\
& Wirausaha & 6 & $4,2 \%$ \\
& Ibu Rumah Tangga & 4 & $2,8 \%$ \\
Freelance, Non job & 3 & $2,1 \%$ \\
& & 4 & $2,8 \%$ \\
\hline
\end{tabular}




\begin{tabular}{clcc} 
Penghasilan/Uang & $<$ Rp. 1.000.000,- & 12 & $8,5 \%$ \\
Saku Perbulan & 1 juta,- s/d Rp. 5 juta & 84 & $59,6 \%$ \\
& $>$ Rp. 5.000.000 & 45 & $31,9 \%$ \\
\hline
\end{tabular}

Berdasarkan data diatas pada tabel 2 diperoleh data sebanyak 46,8\% pada subjek jenis kelamin laki-laki, dengan total 66 responden. Sedangkan, data yang didapat pada subjek dengan jenis kelamin perempuan adalah sebesar 53,2\% dengan total 75 responden. Rentang usia yangdigunakan dalam penelitian ini mengacu pada rentang usia yang digunakan oleh Kementrian Pariwisata Indonesia guna membantu kategorisasi kelompok usia responden. Data yang diperoleh dari penelitian ini responden paling banyak adalah kelompok usia17-24 yang berjumlah 89 responden dengan persentase sebesar $63,1 \%$. Sedangkan paling sedikit berjumlah 1 responden dengan kelompok rentang usia 55-64 dengan persentase 0,7\%. Adapun pada penelitian ini tidak terdapat responden dengan kategori usia di atas 64 tahun. Sebaran daerah asal responden menunjukan responden penelitian paling banyak berasal dari Jakarta dengan total responden sebanyak 61 responden dengan persentase sebesar 43,4\%. Sedangkan responden yang berasal dari Sulawesi dan Bali berjumlah paling sedikit, yaitu berjumlah masing-masing 1 respoden. Responden penelitian ini didominasi oleh jenis pekerjaan atau aktifitas sebagai mahasiswa dengan jumlah sebanyak 80 responden dan persentase sebesar 56,7\%. Sedangkan responden yang paling sedikit pada penelitian ini memiliki status sebagai pelajar yaitu sebanyak 1 responden dengan persentase $0,7 \%$. responden yang memiliki penghasilan/uang saku perbulan mulai dari 1 juta rupiah sampai dengan 5 juta rupiah dengan total sebanyak 84 responden dan memiliki persentase sebesar 59,6\%. Selain itu responden dengan penghasilan/uang saku perbulan lebih dari 5 juta rupiah memiliki 45 responden dengan persentase $31,9 \%$. Adapun pada penelitian ini responden yang memiliki penghasilan/uang saku perbulan kurang dari 1 juta rupiah hanya memiliki 12 responden dengan pesentase sebesar $8,5 \%$. 
Tabel 4.

Kategorisasi subyek

\begin{tabular}{|c|c|c|c|c|}
\hline Variabel & Kategori & $\begin{array}{c}\text { Daerah } \\
\text { Keputusan }\end{array}$ & $\begin{array}{c}\text { Jumlah } \\
\text { Subjek }\end{array}$ & Persentase \\
\hline \multirow{3}{*}{$\begin{array}{l}\text { Destination } \\
\text { image }\end{array}$} & Rendah & $X<22$ & 0 & $0 \%$ \\
\hline & Sedang & $22<X<88$ & 139 & $98,6 \%$ \\
\hline & Tinggi & $\mathrm{X} \geq 88$ & 2 & $1,4 \%$ \\
\hline \multirow{3}{*}{$\begin{array}{l}\text { visiting } \\
\text { Intention }\end{array}$} & Rendah & $X<16$ & 0 & $0 \%$ \\
\hline & Sedang & $16 \leq X<64$ & 138 & $97,9 \%$ \\
\hline & Tinggi & $X \geq 64$ & 3 & $2,1 \%$ \\
\hline \multirow{3}{*}{$\begin{array}{l}\text { Tourist } \\
\text { Expectation }\end{array}$} & Rendah & $x<26$ & 0 & $0 \%$ \\
\hline & Sedang & $26 \leq X<104$ & 119 & $84,3 \%$ \\
\hline & Tinggi & $X \geq 104$ & 22 & $15,7 \%$ \\
\hline
\end{tabular}

Seluruh responden rata-rata memberikan response dalam kategori sedang baik pada variabel citra destination, traveler expectation maupun visiting intention. Tidak ada yang memberikan response dalam kategori rendah.

\section{Hasil dan Pembahasan}

\section{Uji Normalitas}

Uji yang dilakukan guna mengetahui persebaran data dari sebuah kelompok terdistribusi secara normal atau tidak. (Ghozali, 2013). Hal ini sangatlah penting, hal ini dikarenakan data harus memiliki distribusi normal adalah syarat untuk dapat dilakukannya pengujian parametric-test. Uji normalitas diuji menggunakan uji statistic Kolmogorov-smirnov.

\section{Tabel 5.}

One-Sample Kolmogorov-Smirnov Test

\begin{tabular}{|c|c|c|c|c|}
\hline & & $\begin{array}{l}\text { Citra } \\
\text { Destination }\end{array}$ & $\begin{array}{l}\text { Tourist } \\
\text { Expectation }\end{array}$ & $\begin{array}{l}\text { Visiting } \\
\text { Intention }\end{array}$ \\
\hline $\mathrm{N}$ & & 141 & 141 & 141 \\
\hline \multirow[t]{2}{*}{ Normal Parameters ${ }^{\mathrm{a}, \mathrm{b}}$} & Mean & 72.59 & 94.22 & 49.28 \\
\hline & Std. Deviation & 7.261 & 9.307 & 6.230 \\
\hline \multirow[t]{3}{*}{ Most Extreme Differences } & Absolute & .072 & .158 & .121 \\
\hline & Positive & .072 & .147 & .121 \\
\hline & Negative & -.066 & -.158 & -.079 \\
\hline Test Statistic & & .072 & .158 & .121 \\
\hline Asymp. Sig. (2-tailed) & & $.071^{\mathrm{c}}$ & $.000^{\mathrm{c}}$ & $.000^{\mathrm{c}}$ \\
\hline
\end{tabular}

a. Test distribution is Normal.

b. diolah dari data penelitian 
Berdasarkan uji asumsi dapat dilihat normalitas masing-masing variabel. Dari tiga variabel penelitian, hanya variabel destination image yang memiliki nilai normal lebih dari 0.05 sedangkan sebaran data variabel tourist expectation dan visiting intention tidak normal karena kurang dari nilai 0.05 .

\section{Uji Linieritas}

Uji yang dilakukan guna mengetahui ada tidaknya hubungan antar variabel independen, dan apakah hubungan antara kedua variabel yang diteliti mengikuti garis lurus atau tidak (Ghozali, 2013).

\section{Tabel 6.}

Uji Linieritas

\begin{tabular}{|c|c|c|c|c|c|c|c|}
\hline & & & $\begin{array}{c}\text { Sum of } \\
\text { Squares }\end{array}$ & df & $\begin{array}{c}\text { Mean } \\
\text { Square }\end{array}$ & $\mathbf{F}$ & Sig. \\
\hline \multirow{3}{*}{$\begin{array}{l}\text { Visiting } \\
\text { Intention * Citra } \\
\text { Destination }\end{array}$} & Between & (Combined) & 2875.520 & 30 & 95.851 & 4.120 & .000 \\
\hline & Groups & Linearity & 2050.859 & 1 & 2050.859 & 88.153 & .000 \\
\hline & & $\begin{array}{l}\text { Deviation from } \\
\text { Linearity }\end{array}$ & 824.661 & 29 & 28.437 & 1.222 & .227 \\
\hline Visiting & Between & (Combined) & 1966.761 & 28 & 70.241 & 2.269 & .001 \\
\hline Intention * & Groups & Linearity & 765.737 & 1 & 765.737 & 24.730 & .000 \\
\hline $\begin{array}{l}\text { Tourist } \\
\text { Expectation }\end{array}$ & & $\begin{array}{l}\text { Deviation from } \\
\text { Linearity }\end{array}$ & 1201.025 & 27 & 44.482 & 1.437 & .098 \\
\hline Citra & Between & (Combined) & 3467.228 & 28 & 123.830 & 3.544 & .000 \\
\hline Destination * & Groups & Linearity & 2029.415 & 1 & 2029.415 & 58.088 & .000 \\
\hline $\begin{array}{l}\text { Tourist } \\
\text { Expectation }\end{array}$ & & $\begin{array}{l}\text { Deviation from } \\
\text { Linearity }\end{array}$ & 1437.814 & 27 & 53.252 & 1.524 & .066 \\
\hline
\end{tabular}

Berdasarkan tabel 4 diketahui bahwa semua hipotesis yang menghubungkan antar variabel memiliki linieritas berdasarkan nilai linierity kurang dari 0.05 maupun dari nilai deviation from linierity di atas 0.05 .

\section{Uji Hipotesis}


Uji yang dilakukan guna mengetahui apakah hipotesis yang diajukan oleh peneliti dapat diterima atau ditolak, dengan cara mengetahui seberapa kuat peran dari variabel independen terhadap variabel dependen. Nilai koefisien korelasi dapat dicari dengan regresi berganda.

Tabel 7.

Uji Hipotesis

\begin{tabular}{|c|c|c|c|c|c|c|}
\hline Hipotesis & Assosiation & & $\mathbf{R}$ & R Squared & $\begin{array}{c}\text { Adjusted R } \\
\text { Square }\end{array}$ & $\begin{array}{l}\text { Std. Error of } \\
\text { the Estimate }\end{array}$ \\
\hline H1 & $\begin{array}{lr}\text { Tourist } & \text { Expectatio } \\
\text { Citra Destination } \\
\text { Visiting Intention }\end{array}$ & n, & $.617^{a}$ & .381 & .372 & 4.936 \\
\hline $\mathrm{H} 2$ & $\begin{array}{l}\text { Citra Destination } \\
\text { Tourist Expectation }\end{array}$ & * & .524 & .275 & . 270 & 6.204 \\
\hline $\mathrm{H} 3$ & $\begin{array}{l}\text { Visiting Intention * } \\
\text { Tourist Expectation }\end{array}$ & & .375 & .141 & .135 & 5.796 \\
\hline $\mathrm{H} 4$ & $\begin{array}{l}\text { Visiting Intention * } \\
\text { Citra Destination }\end{array}$ & & $.614^{\mathrm{a}}$ & .377 & .373 & 4.934 \\
\hline
\end{tabular}

Berdasarkan tebel 5 diketahui bahwa seluruh hipotesis penelitian terbukti dan signifikan membuktikan asosiasi antar variabel penelitian. Variabel destination image dan tourist expectation bersama2 (simultan) memiliki peran sebesar 0.381 atau $38.1 \%$ terhadap visiting intention. Sedangkan secara parsial diketahui bahwa destination image meiliki peran langsung terhadap visiting intention sebesar $37.7 \%$ sedangkan peran langsung tourist expectation terhadap visiting intention sebesar $14.5 \%$. selain peran langsung dapat pula dilihat peran tidak langsung antara destination image terhadap visiting intention melaui tourist expectation.melalui hasil penelitian ini diketahui juga bahwa destination image meiliki peran terhadap harapan pengunjung sebesar $27.5 \%$.

\section{Pembahasan}

Penelitian ini bertujuan untuk mengetahui peran langsung dan tidak langsung antara destination image dan tourist expectation dengan visiting intention yang melibatkan sebanyak 141 responden penelitian. Adapun hasil yang didapat pada penelitian ini yaitu bahwa terdapat peran destination image dan tourist expectation secara simultan terhadap visiting intention wisatawan Labuan Bajo. 
Sedangkan secara parsial diketahui bahwa destination image memiliki peran terhadap visiting intention begitu pula dengan tourist expectation terhadap visiting intention. Selain peran langsung dapat pula dilihat peran tidak langsung antara destination image terhadap visiting intention melaui tourist expectation, melalui hasil penelitian ini diketahui juga bahwa destination image memiliki peran terhadap tourist expectation.

Penelitian sebelumnya yang dilakukan oleh Abubakar dan Ilkan (2016) menjelaskan bahwa adanya pengaruh keputusan visiting intention wisatawan terhadap destination image. Hasil dari penelitian tersebut menjelaskan bahwa keputusan wisatawan pada saat visiting intention sangat dipengaruhi oleh destination image yang dimiliki oleh tempat wisata tertentu di negara Iran. Penelitian tersebut sependapat dengan penelitian yang dilakukan oleh peneliti dan bisa dikatakan bahwa adanya pengaruh keputusan wisatawan open trip untuk menentukan visiting intention pada sebuah destination image khususnya Labuan Bajo. Seperti yang dijaleskan oleh Rajesh (2013) destination image merupakan sebuah ekspresi pengetahuan, prasangka, kesan, imajinasi dan serta pemikiran yang emosional yang dimiliki oleh individu tentang tempat tertentu. Selain itu citra destinasi adalah perasaan wisatawan tentang kondisi pada destinasi dan mendapakan kesan ketika mereka berada di tempat tujuan mengenai baik atau buruk (Fadiryana dan Chan, 2019). Pengetahuan, prasangka, maupun imajinasi yang dimiliki wisatawan terhadap daerah wisata Labuan Bajo akan mendorong intensi berkunjung wisatawan ke Labuan Bajo, meskippun wisatawan belum memiliki pengalaman langsung berwisata di Labuan Bajo. Visiting intention berdasarkan Theory Planned Behavior sendiri dibentuk melalui tiga dimensi seperti sikap itu sendiri, pengaruh lingkungan seperti keluarga, teman dekat, maupun percieved behaviour control. Dalam konteks visiting intention wisatawan domestik ke Labuan Bajo dapat dipahami bila merujuk pada data demografi yang menunjukan besarnya peran media sosial dan iklan trip Labuan Bajo mempengaruhi keinginan berwisata ke Labuan Bajo. Hal ini diperkuat dengan data terbesar responden adalah generasi milenial (17-24 tahun) yang sangat cepat menerima dan mendapat informasi melalui media sosial seperti Instagram, Twitter, You Tube dan lainnya. Adapun 
penelitian yang dilakukan oleh Whang dkk (2015) menyatakan bahwa visiting intention secara langsung dipengaruhi oleh destination image yang dimiliki oleh turis asing.

Penelitian lainnya mengenai destination image dengan visiting intention dilakukan oleh Jalilvand (2012) hasil dari penelitian tersebut yaitu menyatakan bahwa destination image memiliki pengaruh positif dan signifikan terhadap tujuan wisata untuk menentukan visiting intention mereka (wisatawan) ke tempat yang indah di negara Iran. Kesimpulan penelitian yang dilakukan oleh Jalivand (2012) yaitu destination image merupakan kesan atau sebuah ekspresi yang diperoleh oleh seorang turis dalam perjalanan mereka, maka dari itu dengan adanya destination image dapat mempengaruhi keputusan mengunjungi sebuah tempat wisata. Sama halnya dengan penelitian Jalivan, penelitian yang dilakukan oleh peneliti merupakan gambaran dari destination image yang diperoleh merupakan kesan maupun bayangan ekspresi calon wisatawan dalam perjalanan mereka mengunjungi destinasi wisata Labuan Bajo yang dapat mempengaruhi visiting intention wisatawan.

Penelitian Devi (2014) bertujuan untuk mengindentifikasi destination image dari Jammu City, India. Pada studi ini mengkaji dampak dari destination attributes, destination image, dan tourist satisfaction (mediator) menjadi landasan turis untuk berkunjung ke Kota India. Penelitian tersebut mengungkapkan bahwa hubungan antara Destination Attributes dan Destination Image dimediasi oleh kepuasaan turis (tourist satisfaction). Penelitian yang dilakukan oleh Chen dan Tsai (2007) dengan judul "how destination image and evaluative factors affect behavioral intention?" behavior intention menjelaskan destination image dan visiting intention dapat dikatakan berhubungan baik secara langsung maupun tidak langsung, dalam penelitian ini menyatakan bahwa destination image dipengaruhi oleh kualitas dari perjalanan kemudian nilai yang diterima dapat menimbulkan kepuasan atau kesan dan lalu dapat mempengaruhi visiting intention. Kesimpulan dalam penelitian yang dilakukan oleh Chen dan Tsai (2007) mengatakan bahwa terdapat hubungan destination image dengan visiting intention namun hal tersebut dipengaruhi oleh beberapa faktor lainnya. Selain itu adanya kesamaan ekspersi maupun kesan dalam 
destination image Labuan Bajo baik secara imajinasi maupun dari pengalaman perjalanan yang diperoleh dapat mempengaruhi visiting intention wisatawan. Adapun diketahui bahwa hubungan antara destination image Labuan Bajo terhadap visiting intention wisatawan hanya secara langsung, sedangkan secara tidak langsung terdapat faktor lain yang dapat mempengaruhi destination image Labuan Bajo terhadap visiting intention wisatawan open trip seperti kualitas dari perjalanan, nilai yang diterima, ekspektasi, serta kepuasan.

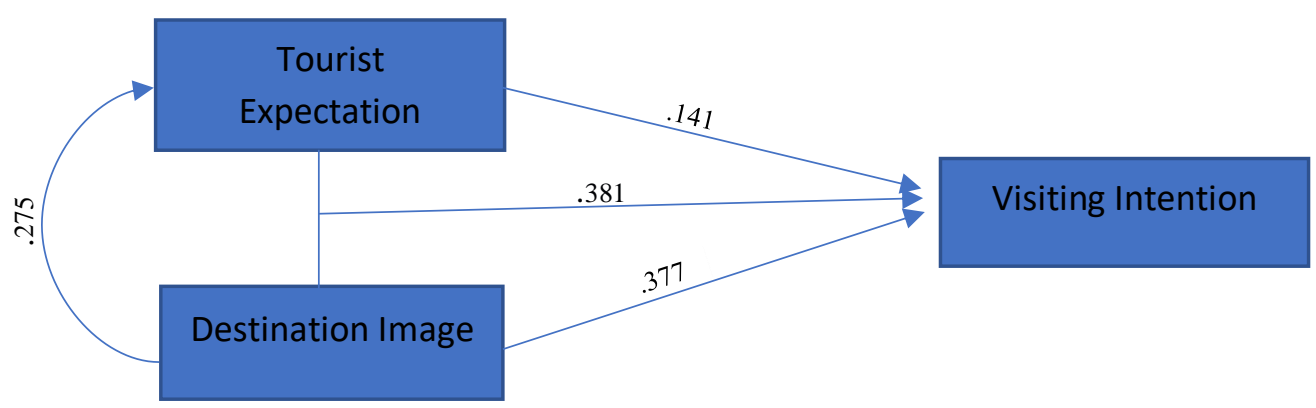

Gambar 1. Hasil Penelitian

Beberapa penelitian menyebutkan korelasi tidak langsung antara destination image dengan visiting intention. Penelitian Valle, Silva, Mendes, Guerreiro (2006) bertujuan untuk mengkaji faktor-faktor yang mempengaruhi loyalitas wisatawan terhadap sebuah destinasi di Arade, Jerman. Salah satu hasil penelitian ini menjelaskan bahwa pada tahap memutuskan berwisata sampai dengan berkunjung dan berulang mengunjungi lokasi wisata terdapat faktor expectasi dan kepuasan berwisata. Tourist expectation menjadi salah satu faktor yang mendorong tourist berwisata. Penelitian Xia, Jie, Chaolin, dan Feng (2009) meneliti dan menguji turis Guilin, China dengan menggunakan tourist expectations, destination image, perceived quality dan perceived value dan konsekuensi dari tourist complain dan tourist loyalty. Salah satu hasil penelitian Xia, dkk (2009) menjelaskan keterkaitan destination image terhadap tourist expectation dimana kedua variabel tersebut menghasilkan loyalitas pada destinasi wisata. Sama halnya dengan hasil penelitian 
ini dimana secara bersama maupun terpisah antara destination image dan tourist expectation memiliki pengaruh pada visiting intention ke Labuan Bajo.

Sejauh ini pengelola wisata mengelola destinasi wisata tanpa memperhatikan tourist expectation pada destinasi wisata. Pada kenyataannya tidak semua wisatawan memiliki keseragaman harapan saat berwisata. Penelitian Nael (Rinuastuti, 2016) membuktikan adanya hubungan nilai budaya dengan kualitas pelayanan, harapan, persepsi, dan niat berperilaku. Hasil beberapa penelitian tersebut menunjukkan bahwa tourist expectation menjadi salah satu faktor penting yang perlu diperhatikan dalam perilaku wisatawan, sehingga diperlukan pengelolaan terhadap tourist expectation. Harapan adalah sesuatu yang konsumen pikirkan harus disediakan oleh penyedia jasa (Hill, 1992). Harapan bukan merupakan prediksi dari apa yang akan disediakan oleh penyedia jasa. Teori harapan Vroom (Vroom's Expectancy Model) menjelaskan pada umumnya manusia memilih salah satu di antara beberapa alternatif perilaku karena manusia tersebut melakukan antisipasi yang secara khusus akan membawa seseorang kepada hasil yang diinginkan. Harapan (expectacy) diyakini sebagai sesuatu yang diinginkan untuk mendapatkan hasil yang maksimal atas perilaku yang dipilih. Dalam konteks pariwisata, sangat penting mengelola tourist expectation karena harapan secara signifikan dapat memengaruhi proses pilihan wisata serta persepsi pengalaman (Gnoth, 1997), dan berimplikasi pada daerah tujuan wisata.

Hasil penelitian ini diperkuat oleh penelitian Sadeh, Asgari, Mousavi, dan Sadeh (2012). Salah satu hasil penelitian Sadeh dkk menunjukan keterkaitan langsung antara destination image terhadap tourist expectation serta peran tidak langsung destination image terhadap visiting intention melalui tourist expectation. Penelitian Sadeh dkk (2012) bertujuan untuk mengkaji faktor-faktor yang mempengaruhi kepuasaan turis dan menjelaskan konsekuensi dari kepuasaan turis. Studi ini mengungkapkan bahwa destination image, harapan turis dan perceived value menjadi faktor yang mempengaruhi kepuasaan turis berujung pada loyalitas destinasi. Ini bermakna citra yang dimunculkan oleh destinasi wisata akan menimbulkan tourist expectation terhadap lokasi wisata yang akan dituju dan pada akhirnya akan mengarahkan wisatawan untuk berwisata. 


\section{Kesimpulan}

Penelitian ini menghasilkan beberapa kesimpulan yang keseluruhan membuktikan hipotesis alternatif dimana variabel destination image dan tourist expectation bersama-sama (simultan) memiliki peran terhadap visiting intention. Sedangkan secara parsial diketahui bahwa destination image memiliki peran terhadap visiting intention begitu pula dengan tourist expectation terhadap visiting intention. Selain peran langsung dapat pula dilihat peran tidak langsung antara destination image terhadap visiting intention melaui tourist expectation, melalui hasil penelitian ini diketahui juga bahwa destination image memiliki peran terhadap tourist expectation.

\section{Saran}

1. Penelitian ini dapat digunakan oleh biro perjalanan, Lembaga Pariwisata untuk tidak mengabaikan destination image dan rourist expectation agar dapat meningkatkan visiting intention wisatawan

2. Untuk Lembaga Pariwisata dan biro perjalanan agar lebih mengenalkan destination image Labuan Bajo khususnya potensi yang dimilikinya dalam bidang pariwisata, alam dan kebudayaan. Serta dapat membuat calon wisatawan tertarik dan ingin berkunjung ke tempat tersebut.

3. Untuk calon wisatawan agar dapat menambah pengetahuan mengenai keinginan untuk berkujung dapat dipengaruhi oleh kesan dari destination image yang dimiliki.

4. Diharapkan untuk penelitian selanjutnya agar mengukur faktor lainnya yang dapat mempengaruhi destination image terhadap visiting intention seperti kualitas dari perjalanan, nilai yang diterima, serta kepuasan wisatasan.

\section{Daftar Pustaka}

Abubakar, M., \& Ilkan, M. (2016). Impact of online WOM on destination trust and intention to travel: A medical tourism perspective. Journal of Destination Marketing and Management 5(3). DOI: 10.1016/j.jdmm.2015.12.005 
Abubakar, M., \& Ilkan, M. (2016). Journal of Destination Marketing \& Management Impact of online WOM on destination trust and intention to travel : A medical tourism perspective. Journal of Destination Marketing \& Management, 1-10. https://doi.org/10.1016/j.jdmm.2015.12.005

Ajzen, I. (1991). The Theory of Planned Behavior. Organizational Behavior and Human Decision Processes, 50.

Ajzen, I. (2005). Attitudes, Personality and Behaviour. (T. Manstead, Ed.) (Second Edi). New York: Open University Press.

Azwar, S. (2012). Reliabilitas dan Validitas. Yogyakarta: Pustaka Pelajar

Bhat, M.A., \& Qadir, N. (2013). Tourist satisfaction in Kashmir: An empirical assessment. DOI: $10.22158 /$ jbtp.v1n1p152

Bhat, A.M., \& Qadir,N.(2013). An Emperical Assessment of Tourists' Expectations and Perceptions. International Journal of Applied Services Marketing Perspectives. Volume 2, Number 2.

Bosque, I.R \& Martín, H.S. (2008). Tourist satisfaction a cognitive-affective model. Annals of Tourism Research. Volume 35, Issue 2. https://doi.org/10.1016/j.annals.2008.02.006

Bosque, I.R., Martin, H.S., Collado, J., \& Salmones, M.M.G ( 2009). A Framework for Tourist Expectations. International Journal of Culture, Tourism, and Hospitality Research. Vol. 3 NO. 2. Emerald Group Publishing Limited

Chen, C., \& Tsai, D. (2007). How destination image and evaluative factors affect behavioral intentions? Tourism Management, 28, 1115-1122. https://doi.org/10.1016/j.tourman.2006.07.007

CNN. (2019). NTT, Destinasi Wisata Terbaik dan Murah Pilihan Lonely Planet. https://www.cnnindonesia.com/gaya-hidup/20191024165021-269442586/ntt-destinasi-wisata-terbaik-dan-murah-pilihan-lonely-planet

Coban, S. (2012). The The Effects of the Image of Destination on Tourist Satisfaction and Loyalty : The Case of Cappadocia. European Journal of Social Sciences, 29 No.2(March 2012). https://www.researchgate.net/publication/267265793\%0AThe 
Devi. Ma., (2014). Empirical Study of Identifying the antecedent and consequences of destination image. International Journal of Innovative Research and studies. Vol.3, Issue.6.

Fadiryana, N.A., dan Chan, S. (2019). Pengaruh Destination Image dan Tourist Experience Terhadap Revisit Intention yang Dimediasi 0leh Perceived Value pada Destinasi Wisata Halal di Kota Banda Aceh. Jurnal Manajemen Inovasi. 10 (2). 1 - 23. P-ISSN 2086-924X.

Ghozali, I. (2013). Aplikasi Analisis Multivariate dengan Program IBM SPSS 21 Update PLS Regresi. Semarang: Badan Penerbit Universitas Diponegoro.

Gnoth, J. (1997). Tourism motivation and expectation formation. Annals of Tourism Research, Vol. 24, No. 2.

Gursoy. D., Chen. JS., Chi. G-Chi. (2014). Theoretical examination of destination loyalty formation. International Journal of Contemporary Hospitality Management. Vol. 26 Iss. 5 http://dx.doi.org/10.1108/IJCHM-12-20130539

Hanif, A., Kusumawati \& Mawardi. (2016). Pengaruh Citra Destinasi Terhadap Kepuasan Wisatwan Serta Dampaknya Terhadap Loyalitas Wisatawan (Studi pada Wisatawan Nusantara yang Berkunjung ke Kota Batu). Jurnal Administrasi Bisnis (JAB), 38(1), 44-52.

Hill, A.V. (1992). Field service management. Illinois: Richard D. Irwin, Inc.

Huang, S. S., \& Veen, R. Van Der. (2018). The moderation of gender and generation in the effects of perceived destination image on tourist attitude and visit intention : A study of potential Chinese visitors to Australia. Journal of Vacation Marketing, 1-15. https://doi.org/10.1177/1356766718814077

Jalilvand, M. R. (2012). The Effect of Electronic Word of Mouth on Brand Image and Purchase Intention : An Empirical Study in The Automobile Industry in Iran. Marketing Intelligence \& Planning. https://doi.org/10.1108/02634501211231946 
Jehane, P. T., Soeprihanto, J., \& Damanik, J. (2019). Penerapan Teori Planned Behavior Dalam Memprediksi Intensi Berkunjung di Objek Wisata Pasar Malam, Kota Kupang. Jurnal Tourism, 02(01), 39-46.

Jusoh, J., Masron, T., Hamid, N.F.A., \& Shahrin, N. (2013). Tourist Expectation and Satisfaction towards Physical Infrastructure and Heritage Elements in Melaka UNESCO World Heritage Site. Academic Journal of Interdisciplinary Studies. Vol 2. No.8. Doi:10.5901/ajis.2013.v2n8p733

Karunia. (2019). Aksesibilitas Hambat Labuan Bajo Jadi Destinasi Super Premium?.

https://money.kompas.com/read/2019/12/11/122102726/aksesibilitashambat-labuan-bajo-jadi-destinasi-super-premium

Margareth. (2019). 5 Wisata Populer NTT Kampung Halaman Johnny G Plate. https://www.tagar.id/5-wisata-populer-ntt-kampung-halaman-johnny-gplate

Myagmarsuren. O., Chen. C.F., (2011). Exploring Relationships between Destination Brand Equity, Satisfaction, and Destination Loyalty: A Case Study of Mongolia. Journal of Tourism, Hospitality \& Culinary Arts. Vol. 3, Issue. 2.

Provisinsi Nusa Tenggara Timur. (2019). Jumlah Wisatawan Mancanegara dan Domestik di Provinsi Nusa Tenggara Timur, 2014-2018. http://nttprov.go.id/2018/index.php/potensi-daerah/pariwisata

Rajesh, R.. (2013). Impact of Tourist Perceptions, Destination Image and Tourist Satisfaction on Destination Loyalty: A Conceptual Model. Revista de $\begin{array}{lllll}\text { Turismo } y & \text { Patrimonio } & \text { Cultural. } & 11 .\end{array}$ https://doi.org/10.25145/j.pasos.2013.11.039

Ramadhan. (2020). Labuan Bajo: Antara Ambisi Wisata Super Premium dan Nasib Warga Lokal. https://www.asumsi.co/post/labuan-bajo-antara-ambisiwisata-super-premium-dan-nasib-warga-lokal

Rinuastuti. (2016). Faktor Pembentuk Harapan Wisatawan; Sebuah Perspektif Lintas Budaya (Studi pada Wisatawan Perancis, Australia, dan Nusantara 
yang Berkunjung di Pulau Lombok). Jurnal Magister Management. 16 (1). DOI: http://dx.doi.org/10.29303/jmm.v16i1.13

Sadeh, E., Asgari, F., Mousavi, L., \& Sadeh, S. (2012). Factors Affecting Tourist Satisfaction and Its Consequences. Journal of basic and applied scientific research 2 (2)

Sugiyono. (2013). Metode Penelitian Pendidikan Pendekatan Kuantitatif, Kualitatif, dan R\&D. Bandung: Alfabeta.

Valle, Silva, Mendes, \& Guerreiro. (2006). Tourist Satisfaction and Destination Loyalty intention: A Structural and Categorical Analysis. International Journal of Business Science and Applied Management. Vol 1. No.1.

Verain, L. (2015). Tourist Motives, Expectations and Satisfaction. Thesis Cultural Geography. Science program 'Leisure, Tourism and Environment' of the Wageningen University and Research Centre.

Wahono. (2012). New 7 Wonders of Nature. https://travel.kompas.com/read/2012/05/16/18073330/Komodo.Resmi.Jadi .New.7.Wonders.of.Nature

Whang, C., Yong, S., \& Ko, E. (2015). Pop culture, destination images, and visit intentions: Theory and research on travel motivations of Chinese and Russian tourists. Journal of Business Research. 69. https://doi.org/10.1016/j.jbusres.2015.06.020

Xia, W., Jie, Z., Chaolin, G., dan Feng, Z. (2009). Examining Antecedents and Consequences of Tourist Satisfaction: A Structural Modeling Approach. Tsinghua Science \& Technology 14(3). DOI: 10.1016/S10070214(09)70057-4. 